\title{
14 \\ Drawing first blood from Maya ceramics at Copán, Honduras
}

\author{
Carney D. Matheson', Jay Hall ${ }^{2}$ and René Viel ${ }^{3}$ \\ 1. Anthropology Department \\ Lakehead University \\ Thunder Bay ON P7B 5E1 Canada \\ Email: cmatheso@lakeheadu.ca \\ 2. School of Social Science \\ The University of Queensland \\ Brisbane, QLD 4072 Australia \\ 3. Copán Formative Project \\ Copán Ruinas, Honduras CA
}

\begin{abstract}
Residue analysis yielded trace blood residues on inside surfaces of four vessels of the Ventaron ceramic type from the Maya site of Copán, Honduras. Microscopy, biochemical detection of the heme subunit of hemoglobin/myoglobin and an immunological test all confirm the presence of blood. This identification supports the hypothesis that the Ventaron vessel type was used for blood ritual purposes during the Classic period.
\end{abstract}

\section{KEYWORDS}

blood residue, ceramics, Maya, Copán

\section{INTRODUCTION}

Molecular archaeology is a developing research field that analyses archaeological remains at the microscopic level for diverse ends relating to past human behavior. One of its main concerns is the identification of organic residues on stone artefacts in order to assess more accurately both their specific functions and their wider roles in past cultural systems (Bahn 1987; Briuer 1976; Cattaneo et al. 1993; Copley et al 2001; Fullagar 1991; Haslam 2003; Kooyman et al. 1992; Kooyman et al. 2001; Loy 1983, 1987; Loy and Dixon 1998; Loy and Hardy 1992). Here we apply this approach to ceramic artefacts and report, for the first time, the discovery of blood residues on Maya ceramic vessels.

Determining the precise function of ceramic wares is a difficult task and Maya vessels are no exception. While a vessel's morphology may suggest its contents at a coarse-grained level and occasional glyphs on Maya pots provide clues to their contents (Stuart 1986, 1988), only microscopic residues can precisely inform us about what a vessel contained and perhaps what it was used for (Hurst et al. 1989; Hall et al. 1990; Henderson et al. 2007). Because prolonged or repeated contact of a particular substance on a ceramic surface will eventually trap and preserve remnants of the substance as a thin residue, modern laboratory techniques allow the identification of the chemical constituents of such residue. These techniques actually identify the molecules that characterize the residue. For example, calcium tartrate, tartaric acid and resins (e.g. terebinth) 
identify fermentation products and wine residues (McGovern 1996; McGovern et al. 1996), theobromine and caffeine identify cocoa residues (Hall et al. 1990; Hurst et al. 1989) and heme and globin molecules serve to identify blood residue (Loy 1992; Loy and Dixon 1998). Blood and other biological fluids can be further identified using techniques such as histological staining and chemical and immunological testing (Bahn 1987; Gurfinkel and Franklin 1988; Kooyman et al. 2001; Loy 1983; Petraglia et al. 1996). Once the nature of the residue is established, further testing can provide information pertinent to the function of ceramic vessels.

Under the umbrella of the University of Queensland's research project at Copán, Honduras, Classic Maya vessels of the Ventaron Ceramic Group were targeted for a pilot residue study aimed at assessing the survival of blood residues on ceramics. The entire known sample at the time of the study comprised five complete vessels, one semi-complete vessel and some 30 small fragments. These vessels, produced during the Acbi Period (AD 400-600) at Copán, are essentially shallow flat-bottomed dishes with low rims (one of them with short supports) that are generally decorated with animal effigies (Viel 1993: Figs 47 \& 48; Viel and Cheek 1983: 573,580). All exhibit a large pouring spout that is level with the bottom of the vessel on one side (Figure 1). Four of them are decorated with bat heads and five with stylized bat wings. This vessel type was selected in order to test Viel's suggestion (1993:89) that it was used in sacrificial contexts for the collection and pouring of blood. Indeed, one of the four specimens available for this study clearly exhibited a reddish pigment stain on a broad section of its inside surface and was thus considered a particularly likely candidate for the test.

Although all four specimens came from the same period in Copán's cultural history, they were excavated at different times in different contexts over past decades (e.g. three were associated with burials [see Viel and Cheek 1983]). Nevertheless, they all underwent similar treatment before being stored for later analysis. Following discovery and extraction by hand, they were removed to the laboratory where they were washed with water and a soft brush to remove adhering soil. For whole vessels such as these, a second cleaning with a dilute alcohol solution was undertaken prior to storing them in a sealed glass cabinet.

\section{METHODS AND RESULTS}

The study involved a battery of six residue-identification techniques including microscopic analysis, staining, three biochemical tests and one immunological test. After gaining access to the vessels from the ceramic collection held at the Center of Investigations of the Honduran Institute of Anthropology and History in Copán Ruinas, Honduras, incident light microscopy
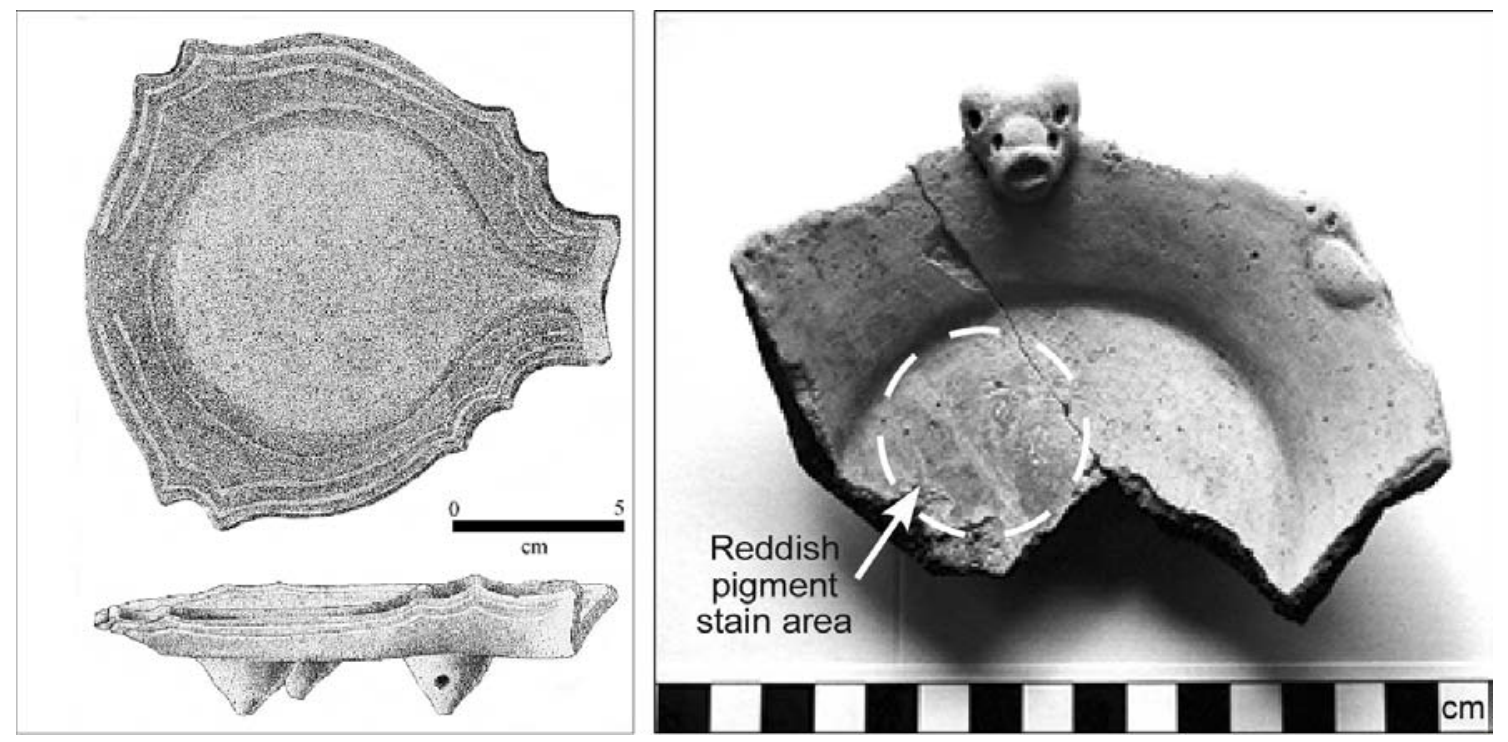

Figure 1. Two of the Ventaron vessels used in this study (left, VV1; right, VV2). 
was employed to determine the presence of residue and its extent. As shown in Table 1, this step revealed residue films that were visually similar to experimental blood films; that is, they appeared dark reddish brown and exhibited the cracking that is characteristic of a protein-rich residue (Loy 1993a, 1993b). Furthermore, anucleated red blood cells were observed within these films, indicating a mammalian origin ('RBC' column, Table 1). This identification was verified by transmitted light microscopy after some of the residue was transferred to a microscope slide and stained with a modified Wright's stain (Loy 1993b).

Table 1. Results of microscopic analysis of Ventaron vessels

\begin{tabular}{|l|l|l|}
\hline Specimen No. & Microscopy result & RBC \\
\hline VV 1 & $\begin{array}{l}\text { Dark globular protein-rich residue. Surface cracking present. Dark } \\
\text { red-brown in colour. }\end{array}$ & Present \\
\hline VV 2 & $\begin{array}{l}\text { Very little residue found \& only in cracks in of the ceramic surface. } \\
\text { Surface cracking present. Dark red- brown in colour. }\end{array}$ & Present \\
\hline VV 3 & $\begin{array}{l}\text { Residue found in small dark red-brown globules. Surface cracking } \\
\text { present in the larger globules. }\end{array}$ & None visible \\
\hline VV 4 & $\begin{array}{l}\text { Large dark red-brown globules with surface cracking present in the } \\
\text { globules. }\end{array}$ & Present \\
\hline
\end{tabular}

Biochemical testing was conducted following the microscopic analyses. Numerous colourimetric techniques have been developed for blood detection, all of which are based on the identification of the heme group of the hemoglobin and myoglobin molecules. This study employed the forensically accepted methods of a phenolphthalein technique (Gurfinkel and Franklin 1988) and a tetramethylbenzidine (TMB) technique (Cox 1991), along with a more easily applied method of a chemical reagent test strip (Hemastix) (Loy 1983; Loy and Wood 1989). The latter method of using chemical reagent test strips has been scrutinised for its accuracy and efficiency (Custer et al 1988; Manning 1994). We present below a modified version of the original method that uses a chelating agent, which has been demonstrated to remove all the cross-reactive possibilities presented as problematic for the method. This modified method works very effectively for the detection of heme-containing units. In this study a sample of residue was first removed from the vessel's surface by applying ultrapure water, allowing the residue to rehydrate with continual agitation with the pipette tip before removal to vials for application to each of the tests. Some samples were also stored for later testing. Samples for heme testing were taken from residue loci identified by microscopy, as well as from non-positive areas including vessel rims and undersides. Randomly selected local soil samples were tested to determine whether or not some constituents of the soil impinging on the vessel surface might produce a positive result.

Phenolphthalein solution was prepared and used following the method outlined by Gurfinkel and Franklin (1988; and Fiori 1962). Aliquots of the aqueous samples removed from the ceramic were placed into a small reaction tube with 2.5 volumes of prepared phenolphthalein solution, which develops a pink colour in the presence of heme. The reaction was scored after 30 seconds using a five-point colour-intensity scale, and then left to fade to ensure any positive reactions were not caused by non-heme substances. If there was no colour change in 30 seconds a volume of $3 \%$ hydrogen peroxide and absolute ethanol (v/v) equal to the volume of phenolphthalein was added to each tube to enhance the colour development.

Aliquots of the aqueous samples were also tested with a tetramethylbenzidine (TMB) solution, which was prepared according to Cox (1991). The samples were placed in separate $1.5 \mathrm{ml}$ sterile tubes with two times the volume of TMB solution. If heme is present, the solution develops a green-blue colour, the intensity of which was recorded against a five-point scale. Because this solution-based test has been shown to react positively with many other substances (Cox 1991; Garner et al. 1976) the sample was also mixed with an equal volume of $500 \mathrm{mM}$ ethylenediaminetetraacetic acid-sodium salt (Na-EDTA). Any non-heme positive results are eliminated by the chelating action of the Na-EDTA. 
Lastly, the residues were analysed using the Hemastix test, which like the TMB test is based on 3,3',5,5'-tetramethylbenzidine (Bayer Diagnostics) but differs in that the sample is applied to a dry reagent test strip. The presence and intensity of a colour change (from yellow to dark green) on the Hemastix strip after 60 seconds was recorded on a scale of 0 (no reaction) to 5 (an instant colour saturation). Although the chemical reagent test strips are more sensitive and easier to use than the phenolphthalein test (Gurfinkel and Franklin 1988), caution must be taken because substances other than heme can produce positive reactions (Cox 1991; Custer et al. 1988; Garner et al. 1976; Gurfinkel and Franklin 1988; Loy 1983; Manning 1994). As in the TMB test above, any non-heme positive reactions were eliminated by repeating the test after mixing the sample with an equal volume of $500 \mathrm{mM}$ Na-EDTA, thereby providing a specific reaction with hemoglobin/myoglobin.

Soil particles adhering to the sides and underside of each vessel as well as one approximately $500 \mathrm{mg}$ bulk soil sample were also analysed using the three biochemical tests reported above. The soil was rehydrated with ultrapure water and processed in the same manner as the aqueous extracts from the vessel surfaces.

Results of the biochemical tests are shown in Table 2. Each test was performed several times on each vessel (see numbers in brackets, Table 2) and they returned a consistent result for the presence of heme in varying concentrations. The Hemastix test strip and the TMB-based solution testing of the microscopically-identified residues fell within the 2-5 range on the colour intensity scale. All control tests performed on the underside of the vessels produced negative results. The soil testing also produced a negative result. When repeated using Na-EDTA the TMB-based tests all produced a colour ranging from 2 to 5 ; nevertheless, the intensity following treatment was reduced because of the repeated resampling of the same location and/or the dilution of the aqueous sample by mixing with the Na-EDTA. All phenolphthalein tests yielded less intense positive results (range $=1-4$; see Table 2 ) than the more sensitive TMB tests, and the negative control remained negative. The greater sensitivity of the TMB tests compared to the phenolphthalein test can be seen in the higher value recorded for Ventaron vessels 1, 2 and 3. However, Gurfinkel and Franklin (1988) state that these tests are less specific for the identification of hemoglobin. Repeating the tests using Na-EDTA provides a more specific reaction with hemoglobin and the results are still an intense reaction. The less sensitive phenolphthalein test and the TMB-based solution test are not as quick and easy to perform as the Hemastix chemical reagent strip test but they have much greater specificity to hemoglobin and their results confirm those of the test strips.

Table 2. Chemical test results

\begin{tabular}{|l|l|l|l|l|l|l|l|l|}
\hline \multirow{2}{*}{ Specimens } & \multicolumn{2}{|l|}{$\begin{array}{l}\text { Chemical reagent } \\
\text { test strips }\end{array}$} & \multicolumn{2}{l|}{$\begin{array}{l}\text { Test strips with } \\
\text { EDTA }\end{array}$} & $\begin{array}{l}\text { TMB solution } \\
\text { test }^{\mathbf{b}}\end{array}$ & $\begin{array}{l}\text { Phenol- } \\
\text { phthalein }\end{array}$ & $\begin{array}{l}\text { Dot-blot SpA } \\
\text { test }\end{array}$ \\
\cline { 2 - 9 } & Residue & Control & Residue & Control & Residue & EDTA & & \\
\hline VV 1 & $3-4(3)$ & $0(3)$ & $3(2)$ & $0(2)$ & $4(1)$ & $2(1)$ & $2(1)$ & Not performed \\
\hline VV 2 & $2-4(2)$ & $0(3)$ & $2-3(2)$ & $0(2)$ & $3(1)$ & $3(1)$ & $1(1)$ & Not performed \\
\hline VV 3 & $2-3(3)$ & $0(3)$ & $2(2)$ & $0(2)$ & $3(1)$ & $2(1)$ & $1(1)$ & Not performed \\
\hline VV 4 & $4-5(6)$ & $0(3)$ & $4-5(3)$ & $0(3)$ & $5(1)$ & $4(1)$ & $4(1)$ & Positive \\
\hline Soil sample & N/A & $0(3)$ & $0(3)$ & $0(3)$ & N/A & $0(1)$ & $0(3)$ & Negative \\
\hline
\end{tabular}

aThe chemical reagent test strips were recorded on a 0-5 scale. $0=$ no color change thus no reaction after 60 seconds. $1=$ a particulate trace reaction. $2=$ a trace but evenly reacting over the whole strip. $3-5$ are grades of intensity above the trace reactions.

${ }^{\mathrm{b}}$ The tetramethylbenzidine solution test and the phenolphthalein test were also recorded on a simple arbitrary 5-point intensity scale for rough comparison with the test strips, however the controls are not shown.

The 'Residue' column is samples removed from locations where microscopy indicated the presence of a potential blood residue. The 'Control' samples are removed from regions of the underside of the vessel in areas where microscopy has shown no residue. The number in brackets indicates the number of tests performed. Due to the small amount of residue on the first three vessels only residue of the fourth vessel was taken for a Staphylococcal protein A test. Again this test confirmed the results of the other tests with the presence of mammalian immunoglobulin $\mathrm{G}$, which is found in blood. 
Stored samples from one vessel (VV4) that produced a positive result for hemoglobin in the biochemical tests were then subjected to a Staphylococcal protein A (SpA) dot-blot test. $\mathrm{SpA}$ is a protein from Staphylococcus aureus that binds to the $\mathrm{F}_{\mathrm{c}}$ region of most mammalian immunoglobulins, and with the highest affinity to immunoglobulin G (IgG) (Forsgren and Söquist 1967; Loy and Dixon 1998; Loy and Hardy 1992; Manning 1994; Tijssen 1985). In this test SpA (supplied by Sigma) is conjugated to colloidal-gold in order to enhance the test's sensitivity. The SpA dot-blot test is used as a multi-species mammalian detection system. Some researchers have shown that SpA can react with many mammalian immunoglobulins, not just IgG (Langone 1982; Lindmark et al. 1983). Nevertheless, there is only weak binding to other modern immunoglobulins (e.g. IgE) (Lindmark et al. 1983) and it would be expected that this affinity would be reduced further in ancient residues. In this test, $10 \mu 1$ of residue is allowed to bind to PVDF membrane (Millipore), then washed and incubated in the colloidal gold SpA solution for IgG detection (following the manufacturer's protocol for detection without blocking). A positive reaction produces a pink colour on the dot blot. SpA dot blot results alone are not sufficient to prove the presence of blood given the weak reaction to other non-blood-borne immunoglobulins. However, given the predominance of IgG in the blood, and considering the concentration that would likely remain in a blood residue, the detection of predominantly IgG can be assumed (Loy and Hardy 1992). In any event, a positive reaction is indicative of the detection of immunoglobulins of mammalian origin.

Only one vessel (VV 4) had sufficient residue aliquots remaining to be analysed with the dot-blot. The residue reaction yielded a pink colour, indicating a positive result, while the associated soil sample remained colourless and was thus negative (Table 2).

In summary, the results of the microscopy, Wright's staining and biochemical and immunological analyses that were carried out in this pilot study demonstrate the presence of blood residues on the Ventaron ceramic vessels. First, microscopy highlighted a number of indicators for blood residues including red-brown pigmentation, a 'cracked-mud' appearance and some red blood cells. The latter were later confirmed by the modified Wright's stain test. Biochemical testing using three different methods, while employing Na-EDTA to eliminate non-hemoglobin reactions in the controversial chemical reagent test strips and the more sensitive TMB-based solution test. These indicated the presence of heme in the residues on the four vessels, but not in the soil or in samples taken from microscopically 'barren' locations. Although only one vessel (VV4) was tested with the SpA colloidal conjugated dot-blot test, the results indicated the detection of immunoglobulins of mammalian origin, which is consistent with the microscopic observations and staining of anucleate red blood cells in the residues.

\section{DISCUSSION}

The results of this pilot study are significant for both their methodological and archaeological implications. First, the results lead us to argue strongly for the possibility that blood residues are preserved after deposition on ceramic material in much the same way as they are on stone (Loy 1983, 1993b; Loy and Dixon 1998). These findings support the proposition by Craig and Collins (2002) that proteinaceous residues can be preserved on ceramic material. We propose that rapid drying and subsequent tertiary denaturation of some of the blood molecules (e.g. serum albumin) creates an unorganized polymer trapping and preserving more resistant molecules (e.g. hemoglobin) by forming a somewhat hydrophobic surface. The tertiary-denatured molecules also bond (presumably through a variety of chemical bonds) to highly charged, surface-reactive clay minerals in the pottery, and subsequent to burial, through bonds with impinging clay and silt particles (Cattaneo et al. 1993).

Craig and Collins (2002) present the best summary for the chemical bonds that may form between a protein residue and the mineral components of ceramic, demonstrated here by the highly resilient binding of the residue to the ceramic surface to survive the depositional environment, 
ground water and in this case the water wash and the mild alcohol wash. However this study's result is contrary to their finding that water is not a good solution for the removal of mineral bound protein. This contrast is most likely due to several differences between the Ventaron samples and those studied by Craig and Collins including: 1) method of preparation of their simulated protein residue; 2) the water removal protocol employed; and 3) differences in ceramic composition. Craig and Collins (2002) simulated a protein residue by heating to $85^{\circ} \mathrm{C}$ for seven days, which they stated may reflect residues associated with ceramic vessels that have been used for cooking. We suggest that the Ventaron vessels have not been used for cooking and have not been heated, and that this distinction may alter the predominant types of bonding between the residue and the mineral, allowing a water solution to extract residues more successfully than in the study by Craig and Collins (2002). Their study's water removal protocol involved submerging finely-ground protein-bound ceramic particles in water and rocking at $4{ }^{\circ} \mathrm{C}$ for a range of different incubation times and is thus quite different from the protocol presented here, which was performed at room temperature with agitation. Finally, the finely-ground ceramic used by Craig and Collins (2002) was identified as quartz and illite which may not represent the mineral composition of the Ventaron ceramics.

The archaeological importance of these results significantly narrows the range of possible functions for the Ventaron vessels at Copán. As it is doubtful that blood appears on the flat internal surfaces of all four vessels by chance, its presence offers a limited number of possibilities including food preparation or meals involving butchered animals, medicinal practices and ritual involving butchered animals or human bloodletting. The fact that a large proportion of Ventaron vessels are decorated with effigy heads and wings of Copán's animal emblem, the bat, is a tantalising one that begs the question as to whether this animal's blood is represented, and if so, how it may have been incorporated into ritual practice at Copán. Whatever the case, the residues detected on the entire Ventaron sample supports the suggestion that they contained blood (Viel 1993:89) and thus do not refute the hypothesis that these vessels were used in a ritual sacrificial context. One additional implication of the preservation of blood proteins on ceramic wares in some quantity is the potential for direct radiocarbon assay using accelerator mass spectrometry (Loy 1993b; Loy et al. 1991). Such dating would assist the correlation of ceramic chronologies with corrected radiocarbon ages.

In closing, we reiterate that this was a pilot study carried out on a small sample of vessels of one ceramic group at Copán. While we claim to have identified mammalian blood on the vessels, we do not claim to have proven their function. We recognize the need for more extensive and thorough testing of these vessels and of a wider selection of ceramic material from the Ventaron Group, as well as perhaps other ceramic groups, before definitive statements about human behaviour can be asserted. We also need to discern the specific origin of the blood, a task that will be undertaken using genetic analysis.

\section{ACKNOWLEDGMENTS}

Our deepest gratitude to the late Tom Loy, without whose inspirational teaching and research input this project would neither have been conceived nor carried out. This research was supported by the Australian Research Council, The University of Queensland Institute for Molecular Biosciences and the Instituto Hondureño de Antropolgía e Historia.

\section{REFERENCES}

Bahn, P.G. 1987. Archaeology: getting blood from stone tools. Nature 330:14.

Briuer, F.L. 1976. New clues to stone tool function: plant and animal residues. American Antiquity 41(4):478-484. 
Cattaneo, C., K. Gelsthorpe P. Phillips and R. J. Sokol 1993. Blood residues on stone tools: indoor and outdoor experiments. World Archaeology 25(1):29-43.

Copley, M.S., P.J. Rose, A. Clapham, D.N. Edwards, M.C. Horton and R.P. Evershed 2001. Detection of palm fruit lipids in archaeological pottery from Qasr Ibrim, Egyptian Nubia. Proceedings of the Royal Society of London Series B Biological Science 268(1467):5937.

Cox, M. 1991. A study of the sensitivity and specificity of four presumptive tests for blood. Journal of Forensic Sciences 36:1503-1511.

Craig, O.E., and M.J. Collins 2002. The removal of protein from mineral surfaces: implications for residue analysis of archaeological materials. Journal of Archaeological Science 29:10771082 .

Custer, J.F., J. Ilgenfritz, and K.R. Doms 1988. A cautionary note on the use of chemstrips for detection of blood residues on prehistoric stone tools. Journal of Archaeological Science 15:343-345.

Fiori, A 1962. Detection and identification of blood stains. In F. Lundquist (ed.) Methods of Forensic Science, pp. 243-290. New York: Interscience.

Forsgren, A., and J. Sjöquist 1967. Protein A from Staphylococcus aureus: reaction with rabbit gamma globulin. Journal of Immunology 99(1):19-24.

Fullagar, R.L.K 1991. The role of silica in polish formation. Journal of Archaeological Science 18:1-24.

Garner,D.D.,K.MCano, R.S.Peimer, and T.E. Yeshion 1976. An evaluation of tetramethylbenzidine as a presumptive test for blood. Journal of Forensic Sciences 21:816-821.

Gurfinkel, D.M., and U.M. Franklin 1988. A study of the feasibility of detecting blood residues on artifacts. Journal of Archaeological Science 15:83-97.

Hall, G.D., S.M. Tarka Jr., W.J. Hurst, D. Stuart and R.E.W. Adams 1990. Cacao residues in ancient Maya vessels from Rio Azul, Guatemala. American Antiquity 55(1):138-143.

Haslam, M. 2003. Evidence for maize processing on 2000-year-old obsidian artefacts from Copán, Honduras. In D. M. Hart and L. A. Wallis (eds) Phytolith and Starch Research in the Australian-Pacific-Asian regions: The state of the art, pp. 153-161. Canberra: Pandanus Books.

Henderson, J.S., R.A. Joyce, G.D. Hall, J. Hurst and P.E. McGovern 2007. Chemical and archaeological evidence for the earliest cacao beverages. Proceedings of the National Academy of Science 104(48):18937-18940.

Hurst, W.J., R.A. Martin, S.M. Tarka Jr. and G.D. Hall. 1989. Authentication of Cocoa in ancient Mayan vessels using HPLC techniques. Journal of Chromatography 466:279-289.

Kooyman, B., M.E. Newman and H. Ceri. 1992. Verifying the reliability of blood residue analysis on archaeological tools. Journal of Archaeological Science 19:265-269.

Kooyman, B., M.E. Newman, C. Cluney, M. Lobb, S. Tolman, P. McNeil and L. V. Hills 2001. Identification of horse exploitation by Clovis hunters based on protein analysis. American Antiquity 66(4):686-691.

Langone, J.J. 1982. Protein A of Staphylococcus aureus and related immunoglobulin receptors produced by Streptococci and Pneumonococci. Advances in Immunology 32:157-252. 
Lindmark, R., K. Thoren-Tolling and J. Sjoquist. 1983. Binding of immunoglobulins to Protein A and immunoglobulin levels in mammalian sera. Journal of Immunological Methods 62:113.

Loy, T.H. 1983. Prehistoric blood residues: detection on tool surfaces and identification of species of origin. Science 220:1269-1271.

Loy, T. H. 1987. Recent advances in blood residue analysis. In W.R. Ambrose and J.M.J. Mummery (eds) Archaeometry: Further Australasian Studies, pp. 57-65. Canberra:Australian National University.

Loy, T.H. 1993a. Prehistoric organic residue analysis: the future meets the past. In W. Ambrose, A. Andrews, R. Jones, A. Thorne, M. Spriggs and D. Yen (eds) A Community of Culture, pp. 56-72. Department of Prehistory, Research School of PacificStudies. Canberra: The Australian National University.

Loy, T.H. 1993b. The artefact as site: an example of the biomolecular analysis of organic residues on prehistoric tools. World Archaeology 25(1):44-63.

Loy, T.H., and E.J. Dixon 1998. Blood residue on fluted points from Eastern Beringia. American Antiquity 63(1):21-46.

Loy, T.H., and B.L. Hardy 1992. Blood residues analysis of 90,000-year-old stone tools from Tabun Cave, Israel. Antiquity 66:24-35.

Loy, T.H., and A.R. Wood 1989. Blood residue analysis at Cayön Tepesi, Turkey. Journal of Field Archaeology 16:451-460.

McGovern, P.E. 1996. Vin Extraordinaire. The Sciences 36: 27-31.

McGovern, P.E., D.L Glusker, L.J Exner and M.M. Voigt 1996. Neolithic resinated wine. Nature $381: 480-481$

Manning, A.P. 1994. A cautionary note on the use of hemastix and dot-blot assays for the detection and confirmation of archaeological blood residues. Journal of Archaeological Science 21:159-162.

Petraglia, M., D. Knepper, P. Glumac, M. Newman and C. Sussman 1996. Immunological and microwear analysis of chipped-stone artifacts from piedmont contexts. American Antiquity 61(1):127-135.

Stuart, D. 1986. The hieroglyphs on a vessel from Tomb 19, Rio Azul. In R.E.W. Adams (ed.) Rio Azul Reports Number 2, the 1984 Season, pp. 117-121. San Antonio: Centre for Archaeological Research University of Texas.

Stuart, D. 1988. The Rio Azul cacao pot: epigraphic observations on the function of a Maya ceramic vessel. Antiquity 62:153-157.

Tijssen, J.M. 1985. Practice and theory of enzyme immunoassays. In R.H. Burdon and P. H. van Knippenberg (eds) Laboratory Techniques in Biochemistry and Molecular Biology, Vol 15. Amsterdam: Elsevier.

Viel, R. 1993. Evolucion de la Ceramica de Copán,Honduras. Instituto Hondureño de Antropología e Historia, Tegucigalpa D.C.

Viel, R. and C.D. Cheek 1983. Sepulturas. In C. Baudez (ed.) Introduccion a la Arqeuología de Copán, pp551-610. Instituto Hondureño de Antropología e Historia y Secretaria de Cultura y Turismo. Tegucigalpa D.C. 